\title{
Medial Prefrontal Cortex Neuronal Activation and Synaptic Alterations after Stress-Induced Reinstatement of Palatable Food Seeking: A Study Using $c$-fos-GFP Transgenic Female Rats
}

\author{
Carlo Cifani, ${ }^{1 *}$ Eisuke Koya, ${ }^{1 *}$ Brittany M. Navarre, ${ }^{1}$ Donna J. Calu, ${ }^{1}$ Michael H. Baumann, ${ }^{1}$ Nathan J. Marchant, ${ }^{1}$ \\ Qing-Rong Liu, ${ }^{1}$ Thi Khuc, ${ }^{1}$ James Pickel, ${ }^{2}$ Carl R. Lupica, ${ }^{1}$ Yavin Shaham, ${ }^{1}$ and Bruce T. Hope ${ }^{1}$ \\ Intramural Research Program, ${ }^{1}$ IIDA/NIH, Baltimore, Maryland 21224, and ${ }^{2} \mathrm{NIMH} / \mathrm{NIH}$, Bethesda, Maryland 20892
}

\begin{abstract}
Relapse to maladaptive eating habits during dieting is often provoked by stress and there is evidence for a role of ovarian hormones in stress responses and feeding. We studied the role of these hormones in stress-induced reinstatement of food seeking and medial prefrontal cortex (mPFC) neuronal activation in $c$-fos-GFP transgenic female rats, which express GFP in strongly activated neurons. Food-restricted ovariectomized or sham-operated $c$-fos-GFP rats were trained to lever-press for palatable food pellets. Subsequently, lever-pressing was extinguished and reinstatement of food seeking and MPFC neuronal activation was assessed after injections of the pharmacological stressor yohimbine $(0.5-2 \mathrm{mg} / \mathrm{kg}$ ) or pellet priming (1-4 noncontingent pellets). Estrous cycle effects on reinstatement were also assessed in wild-type rats. Yohimbine- and pellet-priming-induced reinstatement was associated with Fos and GFP induction in mPFC; both reinstatement and neuronal activation were minimally affected by ovarian hormones in both $c$-fos-GFP and wild-type rats. $c$-fos-GFP transgenic rats were then used to assess glutamatergic synaptic alterations within activated GFP-positive and nonactivated GFP-negative mPFC neurons following yohimbine-induced reinstatement of food seeking. This reinstatement was associated with reduced AMPA receptor/NMDA receptor current ratios and increased paired-pulse facilitation in activated GFP-positive but not GFP-negative neurons. While ovarian hormones do not appear to play a role in stress-induced relapse of food seeking in our rat model, this reinstatement was associated with unique synaptic alterations in strongly activated mPFC neurons. Our paper introduces the c-fos-GFP transgenic rat as a new tool to study unique synaptic changes in activated neurons during behavior.
\end{abstract}

\section{Introduction}

High rate of relapse to maladaptive eating habits during dieting is the main problem for treating excessive eating (Kramer et al., 1989; Peterson and Mitchell, 1999). While clinical evidence indicates that this relapse is often provoked by stress, anxiety, or negative mood states (Grilo et al., 1989; Polivy and Herman, 1999), the neural mechanisms are largely unknown (Nair et al., 2009a). We adapted a rat reinstatement model, commonly used to study drug relapse (Shaham et al., 2003), and used the pharmacological stressor yohimbine to investigate mechanisms of

\footnotetext{
Received Nov. 26, 2011; revised April 27, 2012; accepted May 1, 2012

Author contributions: C.C., E.K., B.M.N., D.J.C., N.J.M., Q.-R.L., C.R.L.,Y.S., and B.T.H. designed research;C.C., E.K., B.M.N., D.J.C., M.H.B., N.J.M., Q.-R.L., and T.K. performed research; J.P. and B.T.H. contributed unpublished reagents/analytic tools; C.C., E.K., B.M.N., D.J.C., M.H.B., N.J.M., Q.-R.L., C.R.L., and Y.S. analyzed data; C.C., E.K., D.J.C., M.H.B., N.J.M., Q.-R.L., C.R.L., Y.S., and B.T.H. wrote the paper.

The work was supported by the Intramural Research Program of the National Institute on Drug Abuse. We thank Dr. Fabio Cruz for technical assistance.

The authors declare no competing financial interests.

${ }^{*}$ C.C. and E.K. contributed equally to this work.

Correspondence should be addressed to either Bruce T. Hope or Yavin Shaham, NIDA/NIH, 251 Bayview Boulevard, Biomedical Research Center, Baltimore, MD 21224. E-mail: bhope@intra.nida.nih.gov or yshaham@intra.nida.nih.gov.

DOI:10.1523/JNEUROSCI.5895-11.2012

Copyright $\odot 2012$ the authors $\quad 0270-6474 / 12 / 328480-11 \$ 15.00 / 0$
}

stress-induced relapse to palatable food seeking during dieting. Yohimbine is an $\alpha-2$ adrenoceptor antagonist that induces stressand anxiety-like states in humans and nonhumans (Bremner et al., 1996a,b) and reliably reinstates food and drug seeking in rats (Shepard et al., 2004; Feltenstein and See, 2006; Ghitza et al., 2006; Richards et al., 2008). Yohimbine-induced reinstatement of food and drug seeking depends on activation of the stress neurohormone corticotropin-releasing factor (Ghitza et al., 2006; Marinelli et al., 2007).

Women may be more vulnerable to stress-induced relapse to unhealthy eating habits due to menstrual cycle-related fluctuations in ovarian hormones. The proportion of women who use dietary supplements and seek dietary treatment is more than twice that of men (Davy et al., 2006; Pillitteri et al., 2008). There is evidence for sex differences and for a role of ovarian hormones in food intake (Nance, 1983; Geary and Asarian, 1999) and reinstatement of drug seeking (Carroll et al., 2004; Lynch, 2006; Becker and $\mathrm{Hu}, 2008)$. However, while yohimbine reliably reinstates food seeking in female rats (Pickens et al., 2012), the role of ovarian hormones in this reinstatement is unknown. Here, we assessed yohimbine-induced reinstatement of food-seeking in ovariectomized (lower than normal physiological levels of estradiol) and sham-operated (normal physiological levels of 
estradiol) rats. Additionally, to determine whether natural fluctuations in ovarian hormones impact yohimbine-induced reinstatement, we tested cycling female rats during the estrous (declining estradiol) and diestrous phases (rising estradiol) of the estrous cycle (Anzalone et al., 2001). Using these experimental manipulations, we also assessed the role of ovarian hormones in reinstatement induced by pellet priming (noncontingent pellet delivery during testing), a manipulation known to reinstate food seeking (de Wit, 1996).

We recently reported that yohimbine-induced activation of dorsal medial prefrontal cortex (mPFC) neurons plays a critical role in yohimbine-induced reinstatement of food seeking in male rats (Nair et al., 2011). Therefore, we studied the role of ovarian hormones in yohimbine-induced mPFC neuronal activation, as well as synaptic physiology of these activated mPFC neurons. For this purpose, we used our newly developed $c$-fos-GFP transgenic rats (see Materials and Methods) that contain a transgene with the $c$-fos promoter (Morgan and Curran, 1991) that induces rapid transcription of the $g f p$ coding sequence in response to strong neuronal activation (Barth et al., 2004). Strongly activated neurons in these rats can be identified by their GFP expression in electrophysiological slice preparations to compare synaptic properties of activated (GFP-positive) neurons and nearby nonactivated (GFP-negative) neurons. We report that yohimbine-induced reinstatement of food seeking is associated with unique synaptic plasticity changes that are induced selectively within mPFC neurons that are strongly activated during the reinstatement test.

\section{Materials and Methods}

\section{Subjects and apparatus}

Female Long-Evans $c$-fos-GFP transgenic $(n=40)$ or wild-type $(n=8)$ rats (NIDA breeding program; $175-275 \mathrm{~g}$ ) were maintained on a reverse $12 \mathrm{~h} \mathrm{light/dark} \mathrm{cycle} \mathrm{(lights} \mathrm{off} \mathrm{at} \mathrm{7:30} \mathrm{or} \mathrm{8:00} \mathrm{A.M.).} \mathrm{All} \mathrm{procedures}$ followed guidelines outlined in the "Principles of laboratory animal care" (NIH publication no. 85-23). Experiments were conducted in standard self-administration chambers (Med Associates). Each chamber had two levers $9 \mathrm{~cm}$ above the floor, but only one lever (the "active," retractable lever) activated the pellet dispenser, which delivered $45 \mathrm{mg}$ food pellets containing $12.7 \%$ fat, $66.7 \%$ carbohydrate and $20.6 \%$ protein (catalog \# 1811155 , TestDiet). This pellet type was chosen based on pellet preference tests in food-restricted female rats, using 6 pellet types (obtained from TestDiet and Bio-Serv) with different compositions of fat $(0-35 \%)$ and carbohydrate ( $45 \%$ to $91 \%$ ) and different flavors (no flavor, banana, chocolate, grape). All rats were weighed daily and food-restricted to 9-11 g/d of Purina rat chow ( $\sim 55-65 \%$ of their daily food intake) during the training phase and $14-16 \mathrm{~g} / \mathrm{d}$ (to maintain stable body weight) during the extinction and reinstatement test phases; the rat chow was given after the daily self-administration sessions. The chronic diet condition was chosen because human studies suggest that dietary restraint leads to increased vulnerability to stress-induced food craving and relapse to palatable food intake (Herman and Polivy, 1975; Polivy and Herman, 1999; Polivy et al., 2005).

\section{Generation of the c-fos-GFP transgenic rats}

Transgenic $c$-fos-GFP transgenic rats contain the same transgene as the $c$-fos-GFP mice described by Barth et al. (2004). The $c$-fos-gfp plasmid was a gift from Dr. Alison Barth, Carnegie Mellon University, Pittsburgh, PA. The HindIII-KpnI fragment containing the $c f o s-g f p$ transgene was injected into pronuclei of fertilized eggs obtained from Long-Evans females. Three founders of 28 pups were genotype-positive for the $c f o s-g f p$ transgene. Two of these founders did not provide pups; thus all results in the present study were obtained from the remaining founder. Tail samples were genotyped at Laragen Inc using eGFP primers (eGFP forward: GACCCTGAAGTTCATCTGCACC and eGFP reverse: CGGGTCTTGTAGTTGCCGTC) and control primers (1260_1a: CCAGACAGCCAC-
CTATGAAGACAT and 1260_2: CCTTCAGCAAGAGCTGGGGAC). All subsequent breeding used hemizygous $c f o s$-GFP male rats paired with wild-type Long-Evans female rats obtained from Charles River Laboratories. Experimental rats were 5-8 generations from the founder.

\section{Ovariectomy surgery and estrous cycle assessment}

Rats in Experiment 1 were anesthetized with intraperitoneal injections of a mixture of sodium pentobarbital and chloral hydrate $(60$ and $25 \mathrm{mg} /$ $\mathrm{kg}$ ). A small $0.6 \mathrm{~cm}$ incision was made on the rat's lower-right abdomen, through the skin, connective tissue and muscle. The ovary, fallopian tube, upper uterine horn and associated fat pad were exteriorized. The uterine artery was tied off with a 3.0 silk suture before the ovary was cut away and discarded. The muscle wall was then closed with 3.0 chromic suture followed by closure of the skin layer with Polyglactin 910 (Vicryl). The procedure was then repeated on the left side. After surgery, rats were given subcutaneous injections of $2 \mathrm{ml}$ of saline to replace lost fluid and then the analgesic buprenorphine $(0.1 \mathrm{mg} / \mathrm{kg}$, s.c. $)$ was injected $30 \mathrm{~min}$ later. Rats were allowed to recover for at least $7 \mathrm{~d}$ and external sutures were removed by postsurgery day 14 .

The nonoperated rats in Experiment 2 underwent a daily vaginal swabbing procedure (between 8:00 and 9:00 A.M.) to determine their estrous cycle phase. A cotton swab dipped in sterile water was gently inserted into each rat's vagina and the collected cells were transferred onto a glass slide for staining/visualization. Estrous cycle phase was determined using established guidelines (Goldman et al., 2007). Briefly, the estrous phase was defined by a predominance of keratinized (i.e., cornified) cells in the smear, the diestrous phase was defined by a predominance of leukocytes, and the proestrous phase by the presence of clusters or strands of round, nucleated, granular appearing epithelial cells. On reinstatement test days only, the rats were swabbed a second time immediately after the test session to confirm their estrous cycle phase during testing. We did not assess reinstatement during the proestrous phase, because we could not verify its existence both before and after the reinstatement test $(\sim 3.5-4 \mathrm{~h}$ apart) in all experimental conditions, resulting in too many missing values for performing a meaningful statistical analysis.

\section{Drugs}

Yohimbine hydrochloride was purchased from Sigma and dissolved in sterile water. Yohimbine doses are based on previous studies (Ghitza et al., 2007; Nair et al., 2008, 2009b; Pickens et al., 2012) and a pilot study with the transgenic $c$-fos-GFP female rats.

\section{GFP quantification}

All procedures described below were performed at room temperature unless specified. Ninety minutes after the start of the test sessions (120 min after yohimbine injections), rats were deeply anesthetized with isoflurane (saturated in air) for $80 \mathrm{~s}$ and perfused transcardially with $100 \mathrm{ml}$ of $0.01 \mathrm{M}$ PBS followed by $400 \mathrm{ml}$ of $4 \%$ paraformaldehyde in $0.1 \mathrm{M}$ sodium phosphate, $\mathrm{pH}$ 7.4. Brains were removed, postfixed in $4 \%$ paraformaldehyde for $2 \mathrm{~h}$, and transferred to $30 \%$ sucrose in $0.01 \mathrm{~m}$ sodium phosphate, $\mathrm{pH} 7.4$, for $48 \mathrm{~h}$ at $4^{\circ} \mathrm{C}$. Brains were subsequently frozen in powdered dry ice and stored at $-80^{\circ} \mathrm{C}$ until sectioning. Thirty $\mu \mathrm{m}$ coronal sections containing the dorsal and ventral mPFC $(\sim+2.28-3.72$ $\mathrm{mm}$, from bregma) (Paxinos and Watson, 2005) were cut in a cryostat (Leica Microsystems Inc.), collected in cryoprotectant (20\% glycerol and $2 \%$ dimethyl sulfoxide in $0.1 \mathrm{M}$ sodium phosphate, $\mathrm{pH} 7.4$ ) and stored at $-80^{\circ} \mathrm{C}$ until further processing. Free-floating sections were washed $3 \times$ 10 min in PBS, mounted onto chrom-alum/gelatin-coated slides, airdried and coverslipped with Vectashield fluorescent mounting medium (H-1400, Vector Labs). Fluorescent images of the dorsal and ventral mPFC were digitally captured using a Qimaging Exi Aqua camera attached to a Zeiss Axioskop 2 microscope with a $5 \times$ objective. GFPpositive nuclei in 1-2 sections of each left and right hemisphere from each rat were automatically counted using iVision MacOS 10.6.2 (version 4.0.15) (BioVision Technologies). GFP fluorescence images were pseudocolored green. Image capture and quantification of GFP-positive nuclei were conducted in a blind manner by C.C. and N.J.M.

\section{Fos immunohistochemistry}

Immunohistochemical procedures were based on our previous studies (Koya et al., 2009; Bossert et al., 2011, 2012; Nair et al., 2011). Immuno- 
labeling for Fos (the protein product of the immediate early gene $c$-fos) was used to identify and quantify Fos expressed in dorsal and ventral $\mathrm{mPFC}$ neurons during the reinstatement tests. Sections were thawed and washed $3 \times 10 \mathrm{~min}$ in PBS, incubated for $1 \mathrm{~h}$ in $3 \%$ normal goat serum (NGS) in PBS with $0.2 \%$ Triton X-100 (PBS-Tx), and incubated overnight at $4^{\circ} \mathrm{C}$ with anti-Fos primary antibody (sc-52, Lot I2209, Santa Cruz Biotechnology) diluted 1:4000 in 1\% NGS in PBS-Tx. Sections were then washed in PBS and incubated for $2 \mathrm{~h}$ with biotinylated anti-rabbit IgG secondary antibody (BA-1000, Vector Labs) diluted 1:600 in 1\% NGS in PBS-Tx. Sections were washed in PBS and incubated in avidinbiotin-peroxidase complex (ABC Elite kit, PK-6100, Vector Laboratories) in PBS containing 0.5\% Triton X-100 for $1 \mathrm{~h}$ and washed in PBS. Sections were developed in $\mathrm{DAB}$ for $\sim 4 \mathrm{~min}$, washed in $\mathrm{PBS}$, mounted onto chrom-alum/gelatin-coated slides and air-dried. The slides were dehydrated through a graded series of alcohol (30, 60, 90, 95, 100, 100\% ethanol), cleared with Citrasolv (Fisher Scientific), and coverslipped with Permount (Sigma). Bright-field images of the dorsal and ventral mPFC were digitally captured using a Qimaging camera attached to a Zeiss Axioskop 2 microscope with a $5 \times$ objective. Labeled Fos-immunoreactive nuclei in 1-2 sections of each left and right hemisphere from each rat were automatically counted using iVision MacOS 10.6.2 (version 4.0.15). Image capture and quantification of Fos-IR nuclei were conducted in a blind manner by C.C. and N.J.M. The number of GFP-positive, Fos-IR and GFP-IR nuclei in the dorsal and ventral $\mathrm{mPFC}$ was determined by calculating the mean value of two hemispheres per rat.

\section{Yohimbine time course and double-labeling immunohistochemistry of Fos and GFP}

Three female $c$-fos-GFP rats were injected with yohimbine $(2 \mathrm{mg} / \mathrm{kg}$, i.p.) and perfused $2 \mathrm{~h}$ after the injections. The mPFC of these rats was sectioned on a cryostat as described above. Sections were then thawed and washed $3 \times 10 \mathrm{~min}$ in Tris-buffered saline (TBS), incubated for $1 \mathrm{~h}$ in $10 \%$ NGS in TBS with $0.2 \%$ Triton X-100 (TBS-Tx), and then incubated in $2 \%$ NGS in TBS-Tx overnight at $4^{\circ} \mathrm{C}$ with rabbit anti-Fos primary antibody (sc-52, Lot D1411, Santa Cruz Biotechnology) diluted 1:500, and chicken anti-GFP primary antibody (GFP-1020, lot 1229FP08, Aves Labs Inc) diluted 1:1000. To detect both GFP-IR and Fos-IR, sections were washed in TBS and incubated for $2 \mathrm{~h}$ in $2 \%$ NGS in TBS-Tx with biotinylated donkey anti-chicken IgG antibody (703-065-155, Jackson ImmunoResearch) diluted 1:200 and then washed in TBS and incubated for another $2 \mathrm{~h}$ in 2\% NGS in TBS-Tx with Alexa Fluor 350-conjugated streptavidin (S11249, Invitrogen) diluted 1:200, and Alexa Fluor 568conjugated goat anti-rabbit IgG antibody (A11011, Invitrogen). Sections were then washed in TBS, mounted onto chrom-alum/gelatin-coated slides, air-dried, and coverslipped with PermaFluor Aqueous Mounting Medium (TA-030-FM, Thermo Scientific). Fluorescent images of the dorsal and ventral mPFC were digitally captured using a Qimaging Exi Aqua Camera attached to a Zeiss AxioImager M.2 microscope with a $10 \times$ objective. GFP-IR and Fos-IR fluorescence images were pseudocolored green and red, respectively. GFP-IR and c-Fos-IR nuclei in 1-2 sections of each left and right hemisphere from each rat were automatically counted using iVision Lab software MacOS 10.6.7 (version 4.0.15).

Fifteen additional naive female $c$-fos-GFP transgenic rats were used for a time course analysis of Fos-IR and GFP-IR induction after yohimbine injections. The rats were transferred to a novel cage and a novel room and immediately injected with yohimbine $(2 \mathrm{mg} / \mathrm{kg}$, i.p.). Subsequently, the rats were perfused either immediately $(0 \mathrm{~h}), 2,6$, or $24 \mathrm{~h}(n=3-4$ per time point) after the injections. The assay conditions were the same as above except that PBS was used instead of TBS.

\section{Radioimmunoassay for corticosterone}

A radioimmunoassay for the stress hormone corticosterone was performed to determine the effect of ovariectomy on yohimbine-induced increases in plasma corticosterone (Suemaru et al., 1989; Marinelli et al., 2007). At the end of Experiment 1, $1 \mathrm{ml}$ of blood was extracted from the right atrium of anesthetized rats and transferred into heparin-treated Microfuge tubes ( $50 \mu$ l of 5000 USP U/ml heparin per tube) immediately before perfusions for immunohistochemistry. The blood samples were centrifuged at $800 \times g$ for $10 \mathrm{~min}$ in a refrigerated Microfuge to separate plasma from cells. Plasma samples $(500 \mu \mathrm{l})$ were stored at $-80^{\circ} \mathrm{C}$ until further processing. Corticosterone levels were then assessed using the radioimmunoassay kit from MP Biomedicals LLC as previously described (Shalev et al., 2003). All plasma samples were run in a single assay using the standard dilution method (samples were diluted 1:200). Mean intra-assay variance was $5 \%$.

\section{Electrophysiology}

Rats received yohimbine ( $2 \mathrm{mg} / \mathrm{kg}$, i.p.) injections $30 \mathrm{~min}$ before the 60 min reinstatement tests. Rats were decapitated immediately after the reinstatement test (90 min after yohimbine injections) and their brains were rapidly removed and immersed in near frozen $\left(1-3^{\circ} \mathrm{C}\right)$ oxygenated high-sucrose artificial CSF (aCSF) containing (in mM) 194 sucrose, 30 $\mathrm{NaCl}, 4.5 \mathrm{KCl}, 1 \mathrm{MgCl}_{2}, 26 \mathrm{NaHCO}_{3}, 1.2 \mathrm{NaH}_{2} \mathrm{PO}_{4}$, and 10 D-glucose saturated with $95 \% \mathrm{O}_{2} / 5 \% \mathrm{CO}_{2}$. Control $c$-fos-GFP transgenic rats and their negative littermates underwent 5-7 d of food deprivation without any food self-administration training, and their brains were removed 90 min later after yohimbine injections $(2 \mathrm{mg} / \mathrm{kg}$, i.p.) in their home cage. Coronal slices $(280 \mu \mathrm{m})$ corresponding to $2.4-4.0 \mathrm{~mm}$ anterior to bregma (Paxinos and Watson, 2005) (containing dorsal mPFC) were prepared using a vibrating tissue slicer (VT1000S; Leica Instruments). Hemisectioned brain slices were stored in a holding chamber containing normal aCSF containing (in mM) $126 \mathrm{NaCl}, 4.5 \mathrm{KCl}, 2.5 \mathrm{CaCl}_{2}, 1 \mathrm{MgCl}_{2}$, $26 \mathrm{NaHCO}_{3}, 1.2 \mathrm{NaH}_{2} \mathrm{PO}_{4}$, and $11 \mathrm{D}$-glucose for $\sim 20 \mathrm{~min}$ at $35^{\circ} \mathrm{C}$ before imaging and recording. One brain slice was transferred to a recording chamber and continuously superfused with normal aCSF $(2 \mathrm{ml} / \mathrm{min})$ and maintained at $30-32^{\circ} \mathrm{C}$ using a temperature-controlled solution heater (TC-234B; Warner Instruments).

All recordings were performed in layers $2 / 3$ of the dorsal $\mathrm{mPFC}$ within $7-8 \mathrm{~h}$ after decapitation. Control rats ranged from 10 to 13 weeks old (mean \pm SEM age: $11.7 \pm 0.5$ weeks), while rats for GFP-positive and GFP-negative neuron recordings ranged from 10 to 22 weeks old (mean \pm SEM age: $14.7 \pm 0.7$ weeks). Brain slices were viewed with an upright Olympus BX51WI microscope with a water-immersion objective $(40 \times$; numerical aperture $=0.80$; LUMPlan Fl), equipped with a spinning disk confocal system (PerkinElmer) and near-infrared differential interference contrast (DIC) imaging capabilities. Confocal and DIC Images were acquired using high-resolution CCD cameras (Hamamatsu). A single brain slice was placed in a submerged perfusion chamber (Warner Instruments) and confocal imaging of mPFC GFP-positive neurons commenced. GFP-positive cells were identified under $488 \mathrm{~nm}$ laser-light and images were acquired using Volocity software (PerkinElmer). Neuronal GFP signals were then superimposed on DIC images of the same neuron. To confirm that the neurons recorded were GFP-positive, an Alexa Fluor 568 dye (Invitrogen) was included in whole-cell pipettes to permit colocalization of the GFP and Alexa Fluor 568 signals (see Fig. $4 D$ ). GFP and Alexa Fluor 568 fluorescence images were pseudocolored green and red, respectively. Cells not exhibiting a GFP signal were considered to be GFP-negative. Data from 1 to 2 GFP-positive and 1-3 GFP-negative cells were obtained from each rat.

Whole-cell recordings of evoked EPSCs in pyramidal neurons of dorsal mPFC layers 2/3 were performed using an Axopatch 200B amplifier (Molecular Devices) and electrodes pulled from borosilicate capillary glass ( $1.5 \mathrm{~mm}$ outer diameter, $0.86 \mathrm{~mm}$ inner diameter). Currents were measured using pipettes in which the tip was filled with an intracellular solution containing the following (in mM): $125 \mathrm{~K}$-gluconate, 10 HEPES, 1 EGTA, $2 \mathrm{MgCl}_{2}, 0.1 \mathrm{CaCl}_{2}, 10 \mathrm{KCl}, 2 \mathrm{Mg}^{2+}$-ATP, $0.2 \mathrm{Na}^{+}$-GTP that allowed firing patterns of neurons to be studied. The remainder of the pipette was "back-filled" with a solution containing the following (in mm): $120 \mathrm{CsMeSO}_{3}, 5 \mathrm{NaCl}, 10$ TEA-Cl, 10 HEPES, 4 QX-314 (Sigma), 1.1 EGTA, $4 \mathrm{Mg}$-ATP, and 0.3 Na-GTP, $0.1 \mu \mathrm{M}$ Alexa Fluor 568, with pH set at 7.2 with $\mathrm{CsOH}$ for voltage-clamp studies. Equilibrium between the back-filled $\mathrm{CsMeSO}_{4}$-containing solution and the tip-filled K-gluconatecontaining intrapipette solution was complete within 15 min of onset of whole-cell access, as confirmed by the absence of action potentials due to inclusion of the quaternary lidocaine derivative QX-314 in the back-fill solution. Pyramidal neurons were identified within the mPFC based on morphology under DIC microscopy (a prominent apical dendrite) and by their distinct firing patterns in response to current injections in 
current-clamp mode (e.g., action potential frequency accommodation). Signals were amplified, filtered at $3-5 \mathrm{kHz}$, digitized at $>10 \mathrm{kHz}$, and recorded via on an A/D board (PCI 6024E, National Instruments) and acquired to a PC hard-drive using Windows-based software (WinWCP, courtesy of Dr. John Dempster, University of Strathclyde, Glasgow, UK; http://spider.science.strath.ac.uk/PhysPharm/). Responses were elicited by stimulation within $100-300 \mu \mathrm{m}$ of the recorded neuron using single bipolar pulses $(0.1 \mathrm{~ms}$ duration $)$ at $0.033 \mathrm{~Hz}$, and theta glass pipettes filled with extracellular solution. Series resistance of the recording was monitored using $-10 \mathrm{mV}$ voltage steps $(200 \mathrm{~ms})$ and only cells maintaining stable access $(<10 \%$ change $)$ were included in the analyses. EPSCs were measured in aCSF-containing picrotoxin (100 $\mu \mathrm{M}$, Sigma) to isolate these currents from $\mathrm{GABA}_{\mathrm{A}}$ receptor-mediated IPSCs. Neurons were voltage-clamped at $-80 \mathrm{mV}$ except where noted. AMPA receptor/ NMDA receptor (AMPAR/NMDAR) current ratios were determined by obtaining an average waveform from 10 recording sweeps of AMPA receptor-mediated EPSCs at $-80 \mathrm{mV}$ and NMDA receptor-mediated EPSCs at $+40 \mathrm{mV}$. The peak AMPA receptor EPSC was divided by the NMDA receptor EPSC, measured $35 \mathrm{~ms}$ following the peak of the AMPA receptor EPSCs. We also computed AMPAR/NMDAR current ratios from the averages of 10 evoked EPSCs at $+40 \mathrm{mV}$ with and without $\mathrm{D}-\mathrm{APV}(50 \mu \mathrm{M}$, Tocris Bioscience) in the aCSF. Mean responses recorded during D-APV application (AMPA receptor-only EPSC) were digitally subtracted from responses recorded without D-APV (AMPA receptor + NMDA receptor EPSC) to determine the NMDAR EPSC. The peak of the AMPA receptor EPSC was divided by the peak of the NMDA receptor EPSC to yield the AMPAR/NMDAR current ratio. Paired-pulse ratios were performed by delivering stimulus trains at 20,40,60, 80, 100, 150, and $200 \mathrm{~ms}$ interstimulus intervals.

\section{Training, extinction, and reinstatement of food-reinforced responding}

The experimental conditions during the training, extinction, and reinstatement phases were similar to those used in our previous studies in male and female rats (Nair et al., 2009b, 2011; Pickens et al., 2012). During all phases, the sessions started $30 \mathrm{~min}$ after rats were placed in the self-administration chambers; 8:30 A.M. for the morning group and $12: 30 \mathrm{pm}$ for the afternoon group.

Training and extinction phases. During the training phase, we first gave the rats $3 \mathrm{~h}$ daily sessions of "autoshaping" for $2 \mathrm{~d}$ during which pellets were delivered noncontingently every $5 \mathrm{~min}$ into a receptacle located near the active lever. Pellet delivery was accompanied by a compound $5 \mathrm{~s}$ tone $(2900 \mathrm{~Hz})$-light $(7.5 \mathrm{~W}$ white light $)$ cue, located above the active lever. Subsequently, we trained the rats to lever-press for the pellets on a fixed-ratio-1, 20 s timeout reinforcement schedule. At the start of each $3 \mathrm{~h}$ session, the red houselight was turned on and the active lever was extended. Reinforced active lever-presses resulted in the delivery of one pellet, accompanied by the compound $5 \mathrm{~s}$ tone-light cue. Active lever presses during the $20 \mathrm{~s}$ timeout or presses on the inactive lever had no programmed consequences. During the extinction phase, lever-presses during the $3 \mathrm{~h}$ sessions led to tone-light cue presentations, but not pellet delivery.

Reinstatement phase. During tests for yohimbine-induced reinstatement, we injected the rats with different yohimbine doses $(0.5,1.0$, or 2.0 $\mathrm{mg} / \mathrm{kg}$, i.p.) or vehicle (sterile water) $30 \mathrm{~min}$ before the start of the test sessions. During tests for pellet-priming-induced reinstatement, we gave the rats 1,2, or 4 noncontingent pellets or no pellets (control condition) within $1 \mathrm{~min}$ after the start of the test sessions. The tests for reinstatement were performed under extinction conditions (lever-presses led to tonelight cue presentations, but not pellet delivery).

\section{Experiment 1. Effect of ovariectomy on reinstatement of food seeking and $\mathrm{mPFC}$ activation}

Experiment 1 included 12 sham and 12 ovariectomized female rats that were repeatedly tested. We first trained the rats for food selfadministration ( 5 sessions). We then tested them for the effect of yohimbine $(0,0.5,1$, and $2 \mathrm{mg} / \mathrm{kg}$, i.p.; counterbalanced order) on ongoing food-self-administration over 8 sessions; yohimbine/vehicle injections were given every other day, and regular training sessions were given in the intervening days. Subsequently, we gave the rats 20 extinction sessions and then tested them for reinstatement under extinction conditions.

During the reinstatement test sessions, which were performed every other day with regular extinction sessions in the intervening days, we injected the rats with vehicle or yohimbine $(0.5,1$, and $2 \mathrm{mg} / \mathrm{kg}$, i.p.; counterbalanced order) or gave them no pellet or pellet priming $(1,2$, and 4; counterbalanced order). After completing the yohimbine- and pellet-priming-induced reinstatement tests, we gave the ovariectomy (OVX) and sham groups a final $90 \mathrm{~min}$ reinstatement test and extracted their brains immediately after testing. We divided the rats in each group into three reinstatement conditions ( $n=4$ per condition): vehicle injection, yohimbine ( $2 \mathrm{mg} / \mathrm{kg}$, i.p.) injection, and pellet priming (4 pellets). The duration of the final reinstatement session was shorter $(90 \mathrm{~min}$ instead of $3 \mathrm{~h}$ ) because of the time course of Fos protein expression, which is maximal 90-120 min after neuronal activation (Curran and Morgan, 1995). At the end of testing, the rats were anesthetized and arterial blood was collected for analysis of plasma corticosterone (see above). The rats were then perfused and their brains were removed for quantification of Fos and GFP.

\section{Experiment 2. Role of estrous cycle in yohimbine and pellet} priming-induced reinstatement of food seeking

In this experiment, we further assessed the role of ovarian hormones in reinstatement of food seeking by determining whether the normal fluctuations in the levels of these hormones, observed across the estrous cycle, would affect yohimbine- or pellet-priming-induced reinstatement. We used a within-subject design with the factors of Estrous Phase (estrous, diestrous), Reinstatement Condition (water injections [control], $2 \mathrm{mg} / \mathrm{kg}$ yohimbine, 4 noncontingent pellets), and Lever (active, inactive). Female rats $(n=8)$ underwent 2 sessions of autoshaping, 10 training sessions, and 11 extinction sessions, using procedures described above. Vaginal swabs were performed each morning to determine the rats' estrous cycle phase. Following extinction of food-reinforced responding, we assessed the effect of declining (estrous phase) or rising (diestrous phase) estradiol levels on yohimbine-induced and pellet priming-induced reinstatement. The rats received either water or yohimbine injections $(2 \mathrm{mg} / \mathrm{kg}$, i.p.) 30 min before the start of the test sessions, or received 4 pellets at the beginning of the test session. Each rat was tested a total of 6 times (3 times in estrous and 3 times in diestrous) and underwent at least one yohimbine-free or pellet-free extinction session between each test. One rat was excluded due to abnormal estrous cycling during the experiment (final $n=7$ ).

\section{Experiment 3. Synaptic properties of $m P F C$ neurons activated during yohimbine-induced reinstatement}

In this experiment, we used the slice electrophysiology procedure described above to characterize the phenotype and synaptic properties of neurons activated during yohimbine-induced reinstatement of food seeking. We used one group of rats $(n=16)$ that were tested for yohimbine-induced reinstatement. The female $c$-fos-GFP transgenic rats underwent the same training, extinction and reinstatement procedures described above. Following extinction of food-reinforced responding, the rats received yohimbine injections $(2 \mathrm{mg} / \mathrm{kg}$, i.p. $) 30$ min before the start of a 60 min test session. Immediately after the test session, rats were decapitated and their brains were immediately removed and processed for slice electrophysiology.

\section{Statistical analyses}

Data were analyzed by ANOVAs using the statistical program SPSS (GLM procedure), and significant main effects and interaction effects $(p<0.05)$ were followed by Fisher PLSD post hoc tests. The dependent measures and the factors used in the statistical analyses are described in the results section below. Because our multifactorial ANOVAs yielded multiple main and interaction effects, we only report significant interaction or main effects that are critical for data interpretation. 
A

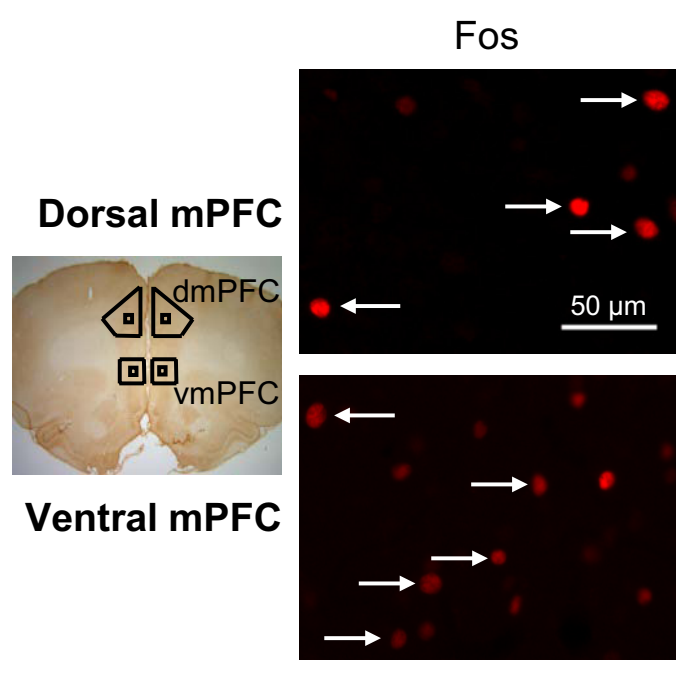

B
Fos-IR+GFP-IR
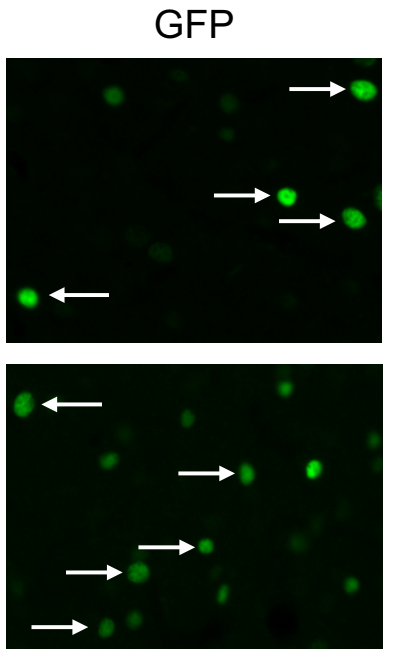

Merge
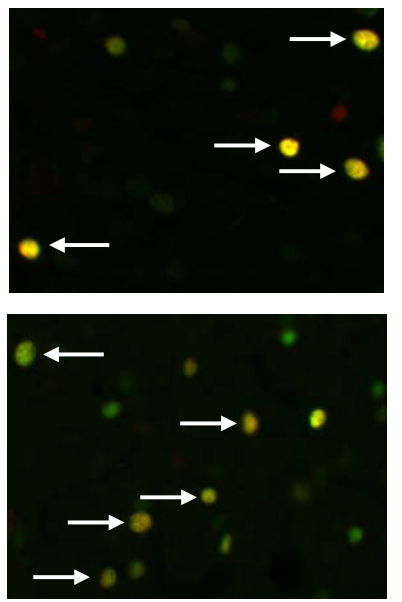

Time course
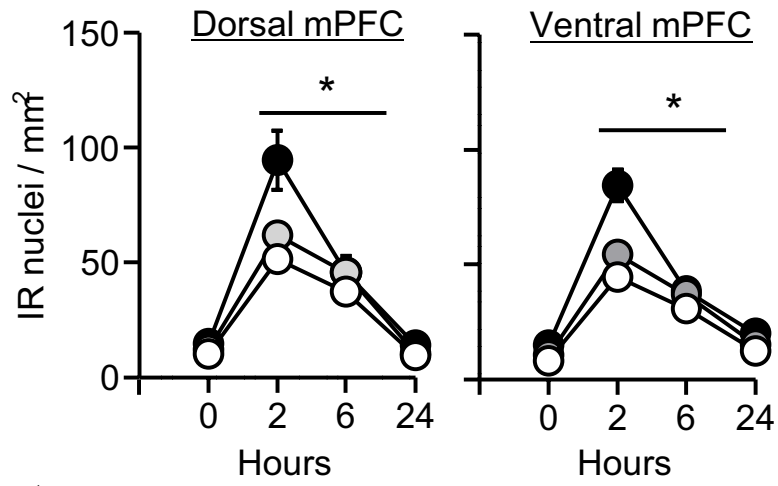

Fos-IR

O GFP-IR

Doublelabeled

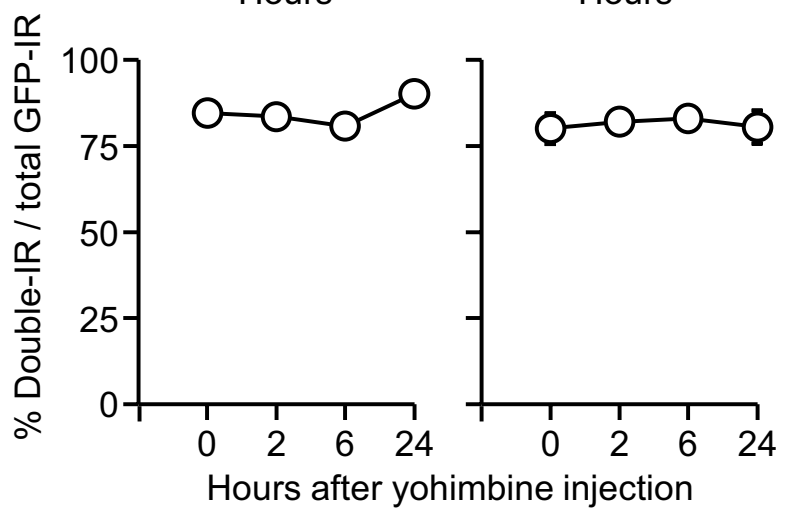

Figure 1. GFP-IR and Fos-IR overlap in mPFC neurons. A, Fos-IR and GFP-IR double labeling: representative photomicrographs of Fos and GFP labeling for dorsal and ventral mPFC (see small squares in the picture on the left of the photomicrographs for approximate areas). Data are from naive rats that were anesthetized and perfused $2 \mathrm{~h}$ after yohimbine ( $2 \mathrm{mg} / \mathrm{kg}, \mathrm{i} . \mathrm{p})$ injections. $\boldsymbol{B}$, Time course of Fos-IR, GFP-IR, and double-labeling after yohimbine ( $2 \mathrm{mg} / \mathrm{kg}$, i.p.) injections. *Different from the 0 and $24 \mathrm{~h}$ time points for Fos-IR, GFP-IR, and double-labeling, $p<0.05, n=3-4$ per time point. dmPFC, Dorsal mPFC; vmPFC, ventral mPFC.

\section{Results}

Fos and GFP induction in mPFC of $c$-fos-GFP transgenic female rats

We initially characterized Fos and GFP induction in $\mathrm{mPFC}$ from 3 naive $c$-fos-GFP transgenic rats. Figure $1 \mathrm{~A}$ shows representative Fos-IR and GFP-IR neurons in ventral and dorsal mPFC of these rats perfused $2 \mathrm{~h}$ after injections of yohimbine $(2 \mathrm{mg} / \mathrm{kg}$, i.p.). We found that, $77 \%$ and $79 \%$ of GFP-IR neurons in dorsal and ventral mPFC were Fos-IR positive. These values are similar to our previous colabeling results for $\beta$-galactosidase-IR and Fos-IR in the mPFC of $c$-fos-lac $Z$ transgenic rats (Bossert et al., 2011). The less than perfect colocalization of GFP-IR and Fos-IR neurons is likely due to differences in antibody sensitivity and the thresholds chosen for each protein when determining whether a nucleus is immunoreactive or not.

We also assessed the time course of Fos and GFP induction in $\mathrm{mPFC}$ after yohimbine injections (Fig. $1 \mathrm{~B}$ ). We injected $15 c$-fos- 
GFP female rats with yohimbine $(2 \mathrm{mg} / \mathrm{kg}$, i.p.) and perfused them either immediately $(0 \mathrm{~h}), 2 \mathrm{~h}, 6 \mathrm{~h}$, or $24 \mathrm{~h}$ after the injections. We found that expression pattern of Fos and GFP showed a similar time course with higher levels 2 or $6 \mathrm{~h}$ after yohimbine injections than 0 or $24 \mathrm{~h}$ after these injections. Additionally, the proportion of GFP-IR cells that coexpressed Fos-IR remained constant over time. ANOVAs of immunoreactive cell counts of the dorsal and ventral mPFC showed significant effects of Time for Fos-IR $\left(F_{(3,14)}=44.3\right.$ and 51.4, $p<0.001$, respectively), GFP-IR $\left(F_{(3,14)}=24.1\right.$ and 71.4, $p<0.001$, respectively), and Fos-IR-GFP-IR double-labeling $\left(F_{(3,14)}=33.5\right.$ and 57.1, $p<0.001$, respectively).

\section{Effect of OVX on reinstatement of food seeking and mPFC activation}

Successful ovariectomy surgery was confirmed by analysis of postmortem uterine weight: $0.38 \pm 0.01$ and $0.01 \pm 0.002 \mathrm{~g}$ in the sham and OVX groups, respectively, $p<0.001$ (One uterus was lost during the postmortem extraction procedure). The successful surgery is also indicated by a significant group differences in body weight $(p<0.001)$. In the Sham group, mean \pm SEM body weight before surgery (free-feeding), the first training day (restricted feeding), and the last reinstatement test day (restricted feeding) was $311 \pm 19,304 \pm 16$, and $301 \pm 11$ g, respectively. In the OVX group, the body weight during these days was $315 \pm 8$, $352 \pm 9$, and $348 \pm 5 \mathrm{~g}$, respectively. OVX had no effect on pellet intake during initial training (Fig. $2 \mathrm{~A}$ ), yohimbine-induced increases in pellet intake during training (data not shown), or extinction of food-reinforced responding (Fig. 2A).

\section{Reinstatement}

OVX had no effect on yohimbine-induced reinstatement but decreased pellet-priming-induced reinstatement (Fig. $2 B, C$ ). The data were analyzed using the between-subjects factor of OVX (OVX, Sham) and the within-subjects factors of Lever (active, inactive) and Yohimbine Dose $(0,0.5,1,2 \mathrm{mg} / \mathrm{kg})$ or Pellet Priming $(0,1,2,4$ pellets). The analysis of the yohimbine data showed a significant interaction of Yohimbine Dose $\times$ Lever $\left(F_{(3,66)}=\right.$ $23.4, p<0.001)$. The analysis of the pellet-priming data showed significant interactions of OVX $\times \operatorname{Lever}\left(F_{(1,22)}=5.9, p=0.024\right)$ and Pellet Priming $\times$ OVX $\times \operatorname{Lever}\left(F_{(3,66)}=2.9, p=0.043\right)$.

\section{mPFC activation}

Yohimbine- and pellet-priming-induced reinstatement was associated with increased GFP expression and Fos-IR in the dorsal and ventral mPFC (Fig. 3). The behavioral data were analyzed using the between-subjects factors of OVX and Reinstatement Condition (vehicle, $2 \mathrm{mg} / \mathrm{kg}$ yohimbine, 4 pellets), and the within-subjects factor of Lever. The ANOVA showed a significant interaction of Reinstatement Condition $\times \operatorname{Lever}\left(F_{(2,18)}=49.5\right.$, $p<0.001$ ) (Fig. 3A). Yohimbine-induced reinstatement induced GFP and Fos expression in the mPFC. Analyses for GFP and Fos quantification included the between-subjects factors of OVX and Reinstatement Condition, and the within-subjects factor of mPFC Region (dorsal, ventral). The ANOVA for the GFP quantification (Fig. $3 B$ ) showed a significant effect of Reinstatement Condition $\left(F_{(2,18)}=20.3, p<0.001\right)$, but no effect of mPFC Region or Reinstatement Condition $\times$ mPFC Region $(p>0.1)$. The ANOVA for the Fos-IR (Fig. 3C) showed significant effects of Reinstatement Condition $\times$ mPFC Region $\left(F_{(2,17)}=19.9, p<\right.$ $0.001)$ and Reinstatement Condition $X$ mPFC Region $\times$ OVX $\left(F_{(2,17)}=4.4, p=0.028\right)$. These interactions are due to somewhat higher baseline and yohimbine-induced Fos-IR in dorsal than in ventral $\mathrm{mPFC}$ and somewhat higher Fos expression in the OVX group than in the Sham group.

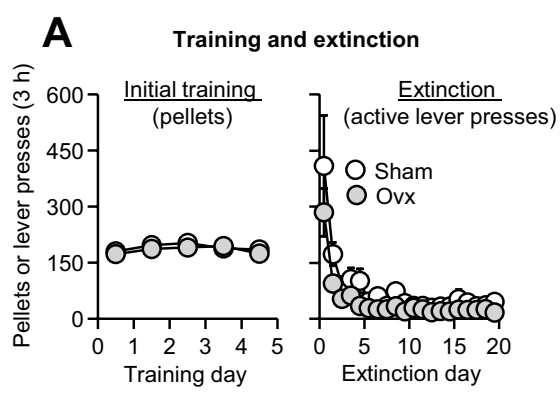

B Yohimbine-induced reinstatement
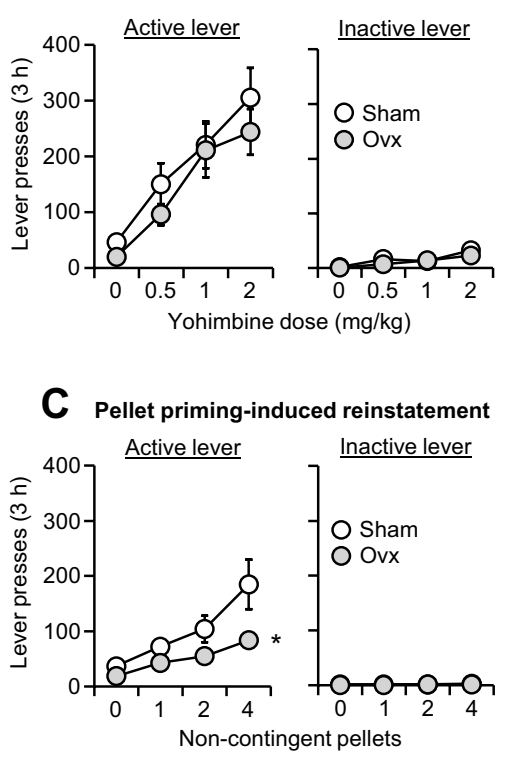

D Reinstatement in cycling females

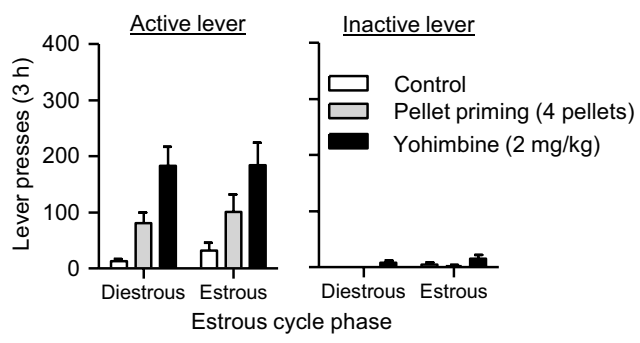

Figure 2. Effect of yohimbine and pellet priming on reinstatement of food seeking in ovariectomized and sham-operated rats and in cycling female rats. $A$, Mean \pm SEM number of food pellets or previously active lever presses during the initial training sessions and the extinction sessions. $\boldsymbol{B}, \boldsymbol{C}$, Mean \pm SEM number of active and inactive lever presses after yohimbine injections or after noncontingent pellet delivery in $0 V X$ and sham rats, $n=12$ per group. $D$, Mean \pm SEM number of active and inactive lever presses in female rats during the estrous and diestrous phases after water injections, yohimbine ( $2 \mathrm{mg} / \mathrm{kg}$, i.p.) injections, or noncontingent delivery of 4 pellets at the beginning of the test session, $n=7$. ${ }^{*}$ Different from the Sham group, $p<0.01$.

\section{Corticosterone}

Yohimbine-induced but not pellet priming-induced reinstatement increased plasma corticosterone secretion $(p=0.01)$, a hormonal measure of the stress response (Selye, 1956), and this effect was not affected by OVX. The mean \pm SEM values $(\mathrm{ng} / \mathrm{ml})$ in the sham group were $334 \pm 58,344 \pm 40$, and $788 \pm 24$ for vehicle, pellet priming, and yohimbine, respectively $(n=4$ per condition). The mean values in the OVX group were $267 \pm 37$, $310 \pm 33$, and $587 \pm 63$ for vehicle, pellet priming, and yohimbine, respectively ( $n=3-4$ per condition). 

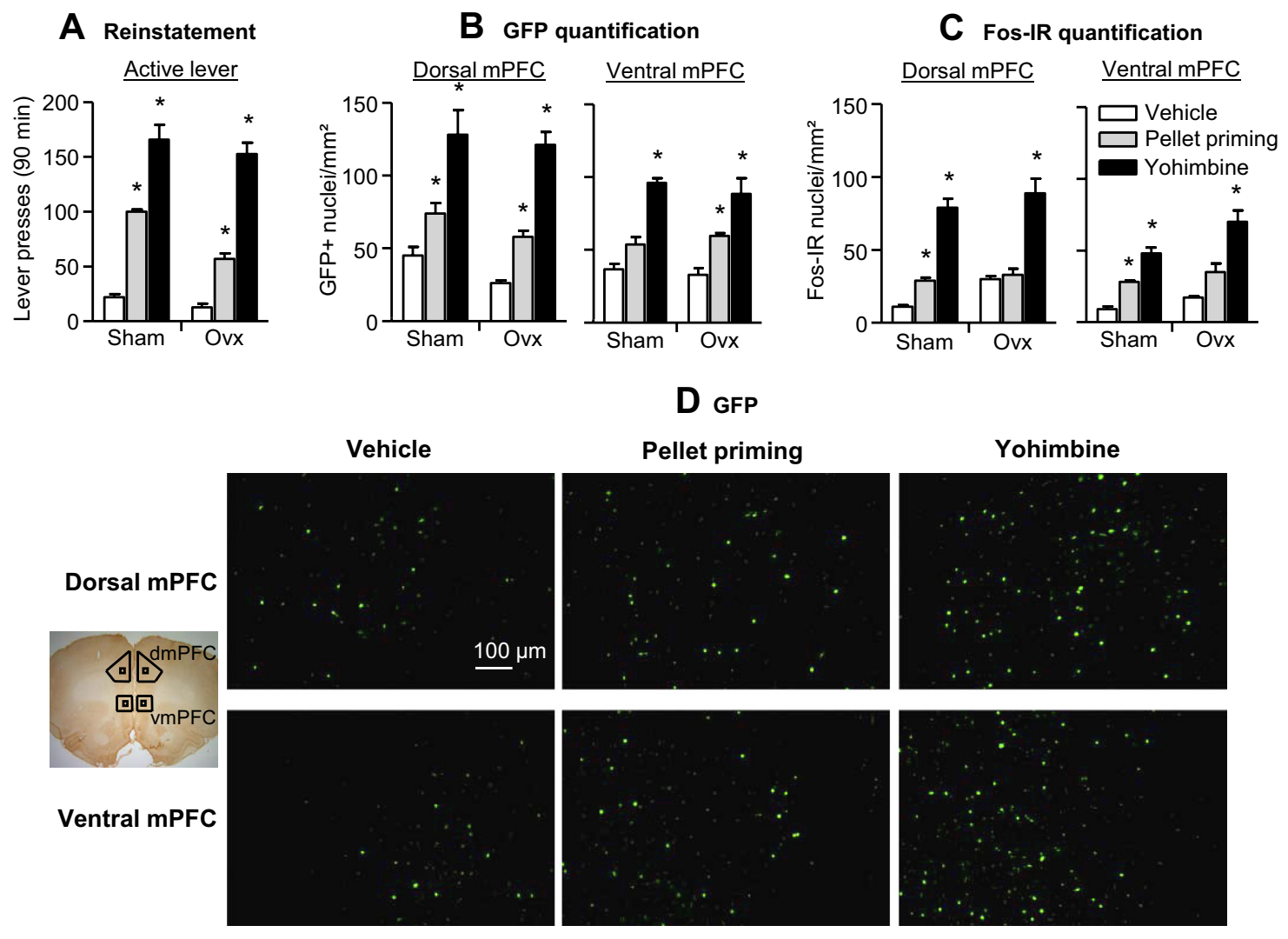

D GFP
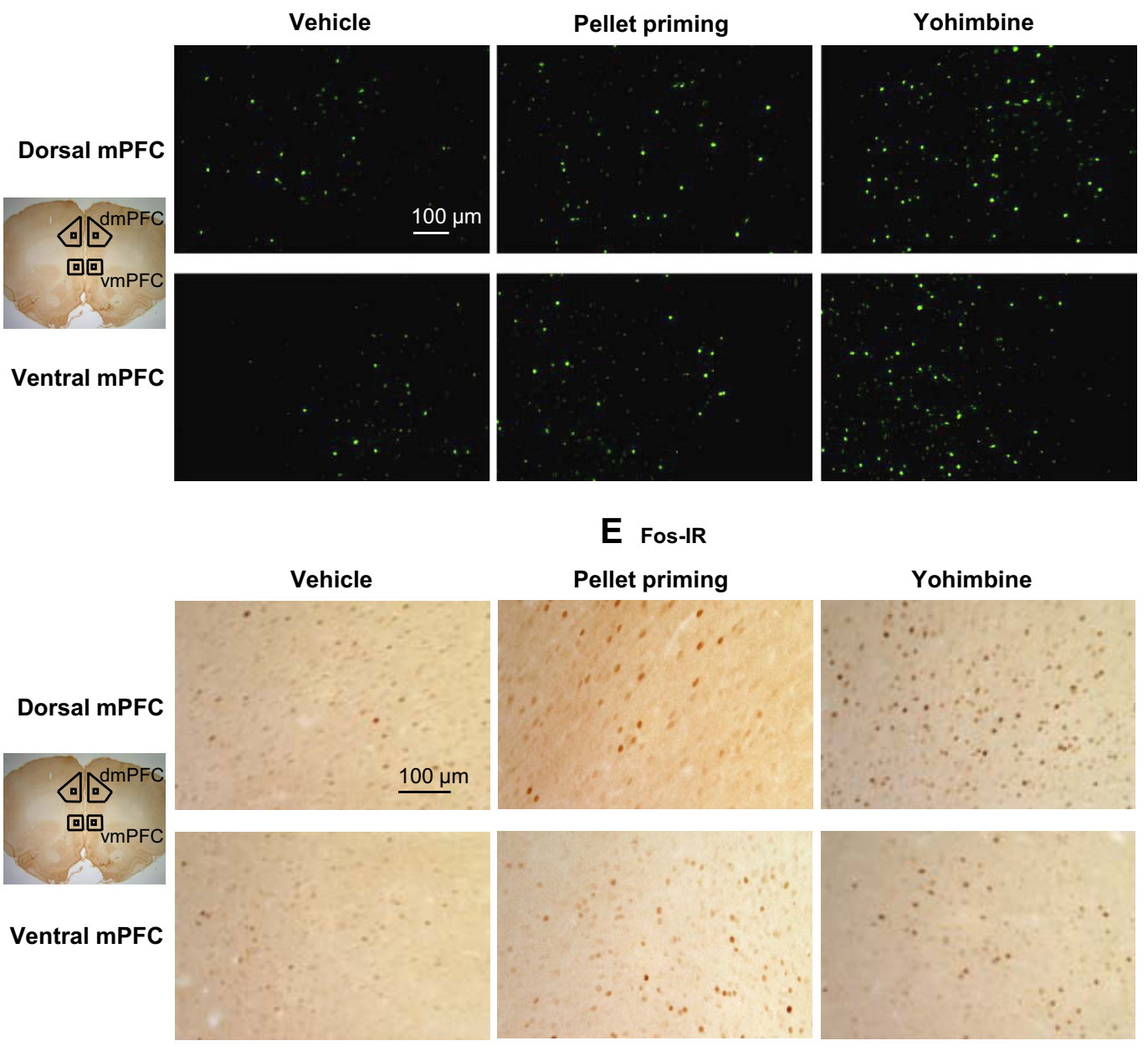

Figure 3. Effect of yohimbine- and pellet priming-induced reinstatement on GFP expression and Fos-immunoreactivity in the dorsal and ventral mPFC. $A$, Mean \pm SEM number of active and inactive lever presses after water (vehicle) injections, yohimbine ( $2 \mathrm{mg} / \mathrm{kg}$, i.p.) injections, and pellet priming ( 4 pellets). $\boldsymbol{B}, \boldsymbol{C}$, Mean \pm SEM number of GFP-positive nuclei (per mm $\left.{ }^{2}\right)(\boldsymbol{B})$ or Fos-IR nuclei $\left(\right.$ per $\left.\mathrm{mm}^{2}\right)(\boldsymbol{C})$ in the dorsal (left) and ventral (right) $\mathrm{mPFC} 90$ min after the test sessions. $\boldsymbol{D}, \boldsymbol{E}$, Representative pictures of GFP-positive $(\boldsymbol{D})$ and Fos-IR $(\boldsymbol{E})$ nuclei in the dorsal and ventral $\mathrm{mPFC}$. *Different from the water (vehicle) condition, $p<0.05$. dmPFC, Dorsal mPFC; vmPFC, ventral mPFC. $n=4$ per experimental condition.

Role of estrous cycle in yohimbine and pellet priming-induced reinstatement of food-seeking

Nonoperated female rats $(n=7)$ were trained for 10 consecutive days $(3 \mathrm{~h} / \mathrm{d})$ to lever-press for food pellets (mean \pm SEM pellet intake over last 4 training days was $191 \pm 20$ pellets per $3 \mathrm{~h}$ ). Leverpressing was then extinguished over 11 consecutive extinction days (mean \pm SEM active lever-presses on the first and last extinction session were $276 \pm 114$ and $16 \pm 5$ per $3 \mathrm{~h}$, respectively). Yohimbine $(2 \mathrm{mg} / \mathrm{kg})$ and pellet priming (4 pellets) reinstated active leverpressing after extinction of the food-reinforced responding and this effect was not dependent on the estrous cycle (Fig. 2D). The data were analyzed using the within-subjects factors of Estrous Phase (es- trous, diestrous), Reinstatement Condition (control, $2 \mathrm{mg} / \mathrm{kg}$ yohimbine, 4 pellets) and Lever. The ANOVA showed significant Reinstatement Condition $\times$ Lever interaction $\left(F_{(2,12)}=13.6, p=\right.$ 0.001 ) but not Estrous Phase or interactions between Estrous Phase and the other factors $(p>0.1)$.

\section{Synaptic properties of mPFC neurons activated during} yohimbine-induced reinstatement

The mean \pm SEM pellet intake over last 4 training days was $181 \pm$ 15 pellet per $3 \mathrm{~h}, n=16$. Lever-pressing was then extinguished during the extinction phase (mean \pm SEM active lever-presses on the first and last extinction sessions were $518 \pm 118$ and $22 \pm 4$ 
A AMPAR/NMDAR current ratios

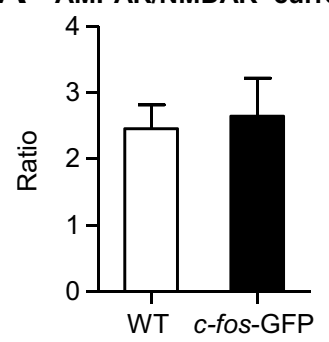

C Reinstatement

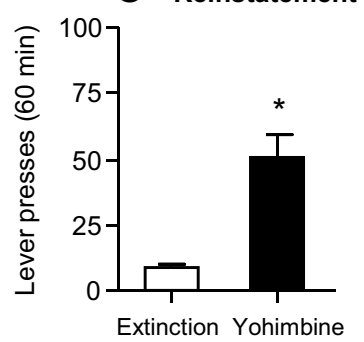

E AMPAR/NMDAR current ratios

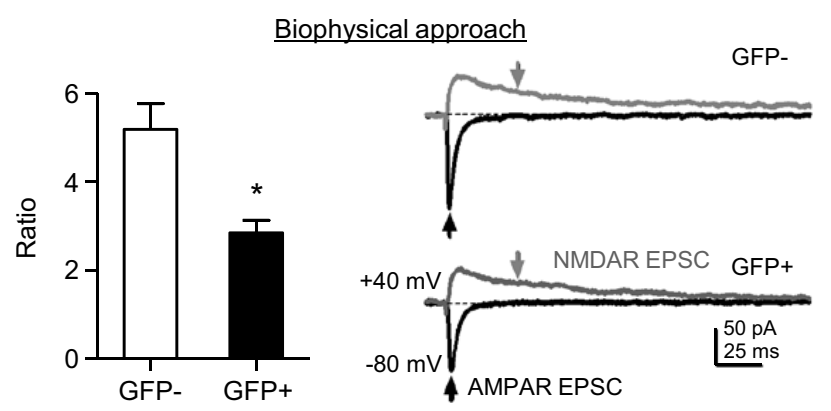

Pharmacological approach
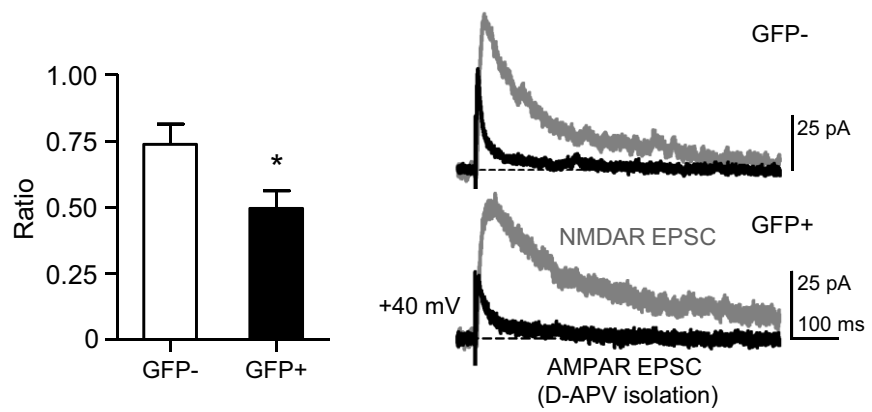

D GFP+ Pyramidal neuron

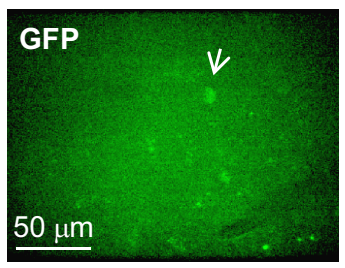

B Paired pulse ratios
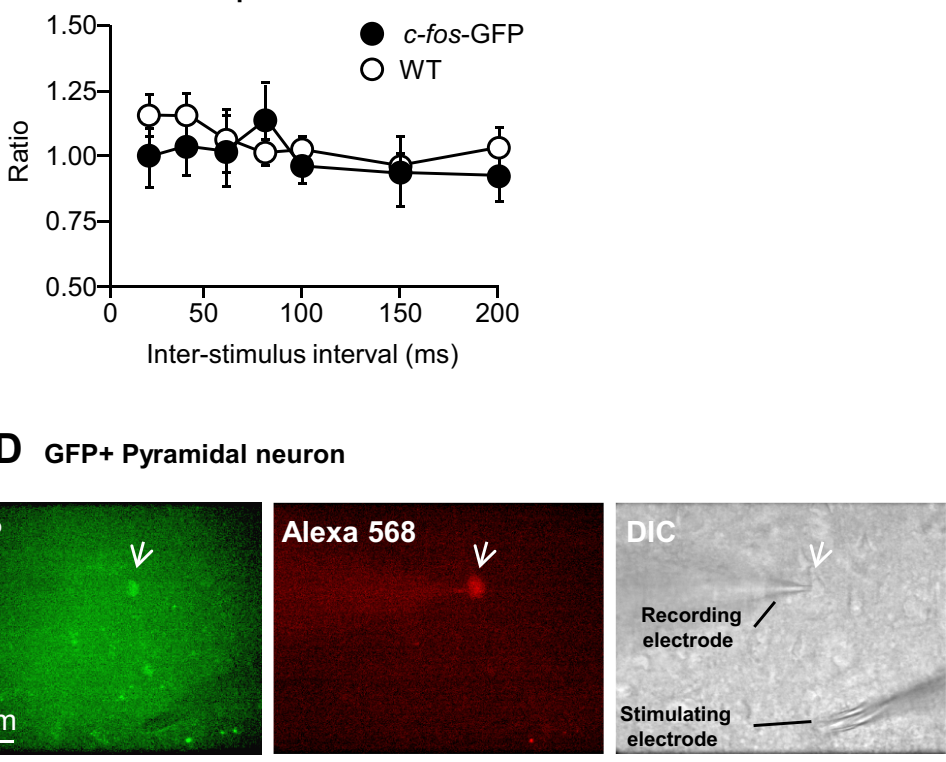

F Paired pulse ratios

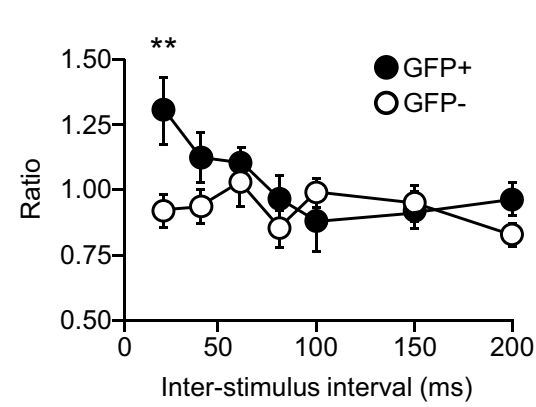

GFP-

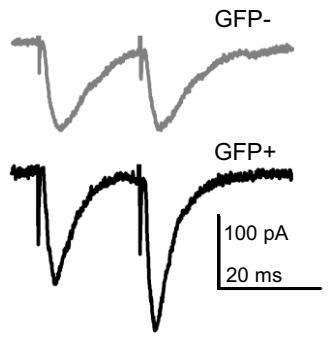

Figure 4. Electrophysiological properties of c-fos-GFP rat dorsal mPFC pyramidal neurons. $A, B$, Mean \pm SEM of AMPAR/NMDAR current ratios ( $\boldsymbol{A})(n=5$ cells $/ 3$ rats for c-fos-GFP transgenic rats; $n=7$ cells $/ 4$ rats for wild-type rats) and paired-pulse ratios from control c-fos-GFP and wild-type rats (B) ( $n=6$ cells $/ 2$ rats for c-fos-GFP rats; $n=10$ cells $/ 4$ rats for wild-type rats) that did not undergo training, but were injected with yohimbine ( $2 \mathrm{mg} / \mathrm{kg}$, i.p.) and killed $90 \mathrm{~min}$ later. $C$, Mean \pm SEM number of active lever presses after water (vehicle) and yohimbine (2 mg/kg, i.p.) injections from c-fos-GFP rats used in Experiment 3. D, Representative micrograph of a GFP-positive pyramidal neuron indicated by a white arrow in the GFP panel. The same neuron was filled with Alexa Fluor 568 included in the patch pipette and indicated by a white arrow in the Alexa Fluor 568 panel. The DIC panel indicates the patched cell and the position of the stimulating and recording electrodes. $\boldsymbol{E}$, Top, Mean \pm SEM of AMPAR/NMDAR current ratios determined using the biophysical approach $(n=5$ cells/4 rats for GFP-negative neurons; $n=4$ cells 33 rats for GFP-positive neurons); the black and gray arrows indicate where the peak AMPAR and NMDAR-mediated EPSC, respectively, were obtained. Bottom, Mean \pm SEM of AMPAR/NMDAR current ratios determined using D-APV application ( $n=10$ cells $/ 6$ rats for GFP-negative neurons; $n=6$ cells $/ 6$ rats for GFP-positive neurons). Example traces of AMPAR and NMDAR-mediated EPSCs are indicated in black and gray, respectively. $\boldsymbol{F}$, Top, Paired-pulse ratios from GFP-negative and GFP-positive neurons ( $n=10$ cells/ 6 rats for GFP-negative neurons; $n=9$ cells $/ 6$ rats for GFP-positive neurons). Bottom, Representative EPSC pairs, evoked with 20 ms interstimulus intervals, are shown for single GFP-positive and GFP-negative pyramidal neurons.

per $3 \mathrm{~h}$, respectively). Yohimbine ( $2 \mathrm{mg} / \mathrm{kg}$, i.p.) reinstated active lever-pressing after extinction of the food-reinforced responding (Fig. $4 C$ ). The statistical analysis comparing the $60 \mathrm{~min}$ yohimbine-induced reinstatement test with the previous first $60 \mathrm{~min}$ of the last extinction session showed a significant effect of Test Ses$\operatorname{sion}\left(t_{15}=5.9, p<0.001\right)$.

We examined glutamate synapses in dorsal mPFC layer $2 / 3$ pyramidal neurons in $c$-fos-GFP rats. To determine whether syn- 
aptic properties were altered in the transgenic rats, we randomly selected and recorded from pyramidal neurons in brain slices from control $c$-fos-GFP rats and wild-type littermates that did not undergo food self-administration training that were killed $90 \mathrm{~min}$ after home-cage yohimbine injections ( $2 \mathrm{mg} / \mathrm{kg}$, i.p.) using only DIC microscopy. AMPAR/NMDAR current ratios were measured, as indicators of changes in synaptic strength (Ungless et al., 2001) by obtaining peak AMPAR- and NMDAR-mediated EPSCs at $-80 \mathrm{mV}$ and $+40 \mathrm{mV}$, respectively. The AMPAR/ NMDAR current ratios did not differ significantly in randomly selected dorsal mPFC neurons between $c$-fos-GFP and wild-type rats (Fig. $4 A, p>0.7$ ). Paired-pulse facilitation, an indicator of presynaptic alterations was also measured in these groups of neurons (Fig. $4 B$ ). Again, no significant effects were observed for the main effects of GFP expression ( $p$ values $>0.5$ ) and interstimulus interval $(p>0.2)$, or an interaction between these two factors $(p>0.5)$. Together, these results indicate that these synaptic parameters were not altered in randomly selected dorsal mPFC neurons of $c$-fos-GFP rats.

To examine the synaptic properties of neurons activated during yohimbine-induced reinstatement of food seeking, we performed whole-cell recordings from both activated GFP-positive and nonactivated GFP-negative pyramidal neurons (Fig. 4D). We determined AMPAR/NMDAR current ratios by obtaining peak AMPAR- and NMDAR-mediated EPSCs at $-80 \mathrm{mV}$ and $+40 \mathrm{mV}$, respectively (Fig. $4 \mathrm{E}$, top), and by pharmacologically isolating AMPA and NMDA currents at $+40 \mathrm{mV}$ (Fig. $4 E$, bottom). In both cases, we found significantly lower ratios in GFPpositive neurons compared with those in GFP-negative neurons (GFP-positive: $2.83 \pm 0.26$, GFP-negative: $5.18 \pm 0.59 ; t_{7}=3.3$, $p=0.013$, Fig. $4 E$, top; GFP-positive: $0.50 \pm 0.06$, GFP-negative: $0.74 \pm 0.07 ; t_{14}=2.51, p=0.025$, Fig. $4 E$, bottom), suggesting a weakening of glutamatergic synaptic strength in GFP-positive neurons. Analysis of paired-pulse data (Fig. $4 F$ ) revealed significant effects of Interstimulus interval $\left(F_{(6,102)}=3.7, p=0.0025\right)$ and GFP expression $\times$ Interstimulus interval $\left(F_{(6,102)}=3.18, p=\right.$ $0.0067)$. Post hoc analysis revealed significant increases in pairedpulse facilitation in GFP-positive neurons at an interstimulus interval of $20 \mathrm{~ms}$ compared with GFP-negative neurons (GFPpositive: $1.30 \pm 0.13$, GFP-negative: $0.92 \pm 0.06 ; t_{17}=3.4, p=$ 0.0128 , Fig. $4 F)$, suggesting decreased presynaptic glutamate release.

\section{Discussion}

We used c-fos-GFP transgenic female rats to assess the role of ovarian hormones in relapse to palatable food seeking and mPFC activation induced by the anxiogenic drug yohimbine, which induces stress-like states in both non-humans and humans (Bremner et al., 1996a,b). Our main novel finding is that yohimbine-induced reinstatement of food-seeking was associated with unique synaptic alterations in activated MPFC neurons that were not observed in nonactivated neurons. Another finding in our study is that ovarian hormones do not play a major role in reinstatement of food seeking during dieting in our rat model.

\section{$c$-fos-GFP transgenic rats}

The endogenous $c$-fos gene is rapidly activated by physiological, pharmacological, and environmental stimuli and serves as a neuronal activity marker (Morgan and Curran, 1991). The development of our $c$-fos-GFP rats was inspired by the $c$-fos-GFP mouse (Barth et al., 2004; Wu et al., 2009) that contains the same transgene with a $c$-fos promoter that rapidly induces the expression of a Fos-GFP fusion protein. A unique advantage of these transgenic rodent models is that the GFP signal can be used to identify neurons that are activated during behavior.

Here we used GFP to identify mPFC neurons that were activated during yohimbine-induced reinstatement of food seeking and to compare glutamatergic synaptic function in these neurons to that of the nonactivated (GFP-negative) neurons. Compared with nearby GFP-negative neurons in the MPFC, GFP-positive neurons exhibited increased paired-pulse facilitation, indicative of a decrease in synaptic glutamate release (Mennerick and Zorumski, 1995), and reduced AMPAR/NMDAR current ratios, which is consistent with a reduction in glutamatergic synaptic strength (Ungless et al., 2001; Malinow and Malenka, 2002). Thus, strongly activated mPFC neurons exhibit presynaptic and postsynaptic alterations at glutamatergic synapses that are not observed in the majority of nonactivated (or less activated) surrounding neurons.

The increased paired-pulse facilitation and the decreased AMPAR/NMDAR current ratio may reflect a homeostatic adaptation of glutamate synapses (Ishikawa et al., 2009; Wolf and Ferrario, 2010; Huang et al., 2011) in response to strong acute activation during the yohimbine-induced reinstatement test. Alternatively, the unique synaptic properties of the GFP-positive neurons may reflect basal synaptic alterations that occurred during food self-administration and extinction of food-reinforced responding. Regardless of the exact mechanism, our study highlights the importance of selectively examining behaviorally activated neurons by showing that their properties are different from the surrounding nonactivated (or less activated) GFP-negative neurons.

To date, studies that have examined acute synaptic plasticity immediately after reinstatement of reward seeking have been performed in rats (Van den Oever et al., 2008, 2010a). In these studies, as well as many other drug self-administration studies (Kalivas, 2009; Bowers et al., 2010; Wolf and Ferrario, 2010; Van den Oever et al., 2010b), synaptic alterations were observed in a general population of neurons using whole-cell recordings from randomly selected cells, regardless of their activation state during behavior. Thus, information pertaining to behaviorally relevant strongly activated neurons (as indicated by $c$-fos expression), which likely mediates reward seeking (Bossert et al., 2011) could not be obtained. The $c$-fos-GFP transgenic rats, as well as the recently developed $c$-fos-monomeric red fluorescent protein 1 (mRFP1) transgenic rats (Fujihara et al., 2009), can be used to provide fundamentally new information on the unique synaptic alterations of these putative behaviorally relevant neurons.

\section{Role of ovarian hormones in reward seeking}

Sex differences and ovarian hormones play a role in food intake (Nance, 1983; Asarian and Geary, 2006) and drug seeking (Carroll et al., 2004; Becker and Hu, 2008), including yohimbineinduced reinstatement (Anker and Carroll, 2010; Feltenstein et al., 2011). A main conclusion from the drug studies is that female rats are more vulnerable than male rats to the initiation, maintenance, and relapse of drug-seeking behaviors (Lynch, 2006; Becker and $\mathrm{Hu}, 2008$ ). Based on these findings, and the emerging neurobiological similarities between palatable food- and drugtaking behaviors (DiLeone et al., 2003; Johnson and Kenny, 2010; Kenny, 2011), a somewhat surprising finding in our study was the minimal impact of ovariectomy on food-reinforced responding during training, extinction responding, and reinstatement.

In reconciling our data with these previous results, several issues should be considered. First, studies on the role of ovarian hormones in food intake have primarily assessed home-cage 
feeding (Geary and Asarian, 1999; Asarian and Geary, 2006) that likely involves neuronal and psychological mechanisms that are different from those controlling operant food-seeking behaviors (Figlewicz et al., 2007; Nair et al., 2009a; Figlewicz and Sipols, 2010). Second, in the case of drug seeking, conclusions regarding sex differences and the role of ovarian hormones in drug seeking are primarily based on studies using cocaine. There are differences between the mechanisms underlying reward and relapse to cocaine compared with reward and relapse to opiates and other drugs of abuse (Badiani et al., 2011). Relevant here are the findings that manipulations of ovarian hormones had no effect on heroin self-administration (Stewart et al., 1996) and that the estrous cycle had no effect on yohimbine-induced reinstatement of nicotine seeking (Feltenstein et al., 2012). Third, in a recent study we assessed sex differences in food-reinforced responding, extinction responding, and yohimbine- and pellet-priminginduced reinstatement, and found no evidence for increased food-seeking behavior in female rats compared with male rats (Pickens et al., 2012). Additionally, while comparison across studies should be made with caution, the magnitude of yohimbine-induced mPFC Fos expression in the current study was similar to that we previously observed in male rats (Nair et al., 2011).

Together, a tentative conclusion from the above studies is that while ovarian hormones and sex differences play an important role in vulnerability to cocaine-seeking behaviors, this may not be the case for nicotine, opiates, and palatable food.

\section{Methodological considerations}

One issue is that the rats were tested repeatedly for both yohimbine- and pellet-priming-induced reinstatement. However, it is unlikely that habituation to repeated testing confounded data interpretation. Internal analyses of both the present data and a recent study in which we used a similar repeated measures design (Pickens et al., 2012) indicate neither habituation nor sensitization of yohimbine- or pellet-priming-induced reinstatement over repeated testing.

Another issue is the relatively small sample size in the immunohistochemistry assays and the electrophysiology experiments. It is unlikely that a larger number of subjects in the immunohistochemistry experiment will change data interpretation. As can be seen in Figure 3, yohimbine induced reliable increases in Fos and GFP expression that were of similar magnitude in the ovariectomized and sham-operated rats, which mirrored the behavioral results. The yohimbine-induced Fos expression data are also in agreement with our findings with nonoperated male rats (Nair et al., 2011), with the exception that the difference between dorsal (higher) and ventral (lower) mPFC in the female rats was less pronounced than in the male rats. Similarly, while the numbers of cells in the GFP-positive and GFP-negative groups in the electrophysiology experiment are relatively low, the data appear robust with relatively low variability across the cells in each experimental group. However, an unresolved interpretation issue in the electrophysiology experiment is whether yohimbineinduced synaptic alterations in mPFC activated neurons are due to the drug's effect on the motivation to seek food or are due to the unconditioned pharmacological effects of yohimbine, which include stimulation of pyramidal cell firing (Wang et al., 2010).

\section{Concluding remarks}

We studied the role of ovarian hormones in stress-induced reinstatement of food seeking and mPFC activation in c-fos-GFP transgenic rats, using yohimbine as a pharmacological stressor and a recently validated rat model (Pickens et al., 2012). Our main finding is that yohimbine-induced reinstatement of food seeking was associated with distinct synaptic alterations in activated GFP-positive versus nonactivated GFP-negative neurons. Based on these data, we propose that the $c$-fos-GFP transgenic rat can be used as a novel tool to study synaptic alterations in activated neurons following reinstatement of reward seeking and other learned behaviors that cannot be readily adapted to $c$-fosGFP transgenic mice (Barth et al., 2004; Yassin et al., 2010).

\section{References}

Anker JJ, Carroll ME (2010) Sex differences in the effects of allopregnanolone on yohimbine-induced reinstatement of cocaine seeking in rats. Drug Alcohol Depend 107:264-267.

Anzalone CR, Hong LS, Lu JK, LaPolt PS (2001) Influences of age and ovarian follicular reserve on estrous cycle patterns, ovulation, and hormone secretion in the Long-Evans rat. Biol Reprod 64:1056-1062.

Asarian L, Geary N (2006) Modulation of appetite by gonadal steroid hormones. Philos Trans R Soc Lond B Biol Sci 361:1251-1263.

Badiani A, Belin D, Epstein D, Calu D, Shaham Y (2011) Opiate versus psychostimulant addiction: the differences do matter. Nat Rev Neurosci 12:685-700.

Barth AL, Gerkin RC, Dean KL (2004) Alteration of neuronal firing properties after in vivo experience in a FosGFP transgenic mouse. J Neurosci 24:6466-6475.

Becker JB, Hu M (2008) Sex differences in drug abuse. Front Neuroendocrinol 29:36-47.

Bossert JM, Stern AL, Theberge FR, Cifani C, Koya E, Hope BT, Shaham Y (2011) Ventral medial prefrontal cortex neuronal ensembles mediate context-induced relapse to heroin. Nat Neurosci 14:420-422.

Bossert JM, Stern AL, Theberge FR, Marchant MJ, Wang HL, Morales M, Shaham Y (2012) Role of projections from ventral medial prefrontal cortex to nucleus accumbens shell in context-induced reinstatement of heroin seeking. J Neurosci 32:4982-4991.

Bowers MS, Chen BT, Bonci A (2010) AMPA receptor synaptic plasticity induced by psychostimulants: the past, present, and therapeutic future. Neuron 67:11-24.

Bremner JD, Krystal JH, Southwick SM, Charney DS (1996a) Noradrenergic mechanisms in stress and anxiety: I. preclinical studies. Synapse 23:28-38.

Bremner JD, Krystal JH, Southwick SM, Charney DS (1996b) Noradrenergic mechanisms in stress and anxiety: II. Clinical studies. Synapse 23: $39-51$.

Carroll ME, Lynch WJ, Roth ME, Morgan AD, Cosgrove KP (2004) Sex and estrogen influence drug abuse. Trends Pharmacol Sci 25:273-279.

Curran T, Morgan JI (1995) Fos: an immediate-early transcription factor in neurons. J Neurobiol 26:403-412.

Davy SR, Benes BA, Driskell JA (2006) Sex differences in dieting trends, eating habits, and nutrition beliefs of a group of midwestern college students. J Am Diet Assoc 106:1673-1677.

de Wit H (1996) Priming effects with drugs and other reinforcers. Exp Clin Psychopharmacol 4:5-10.

DiLeone RJ, Georgescu D, Nestler EJ (2003) Lateral hypothalamic neuropeptides in reward and drug addiction. Life Sci 73:759-768.

Feltenstein MW, See RE (2006) Potentiation of cue-induced reinstatement of cocaine-seeking in rats by the anxiogenic drug yohimbine. Behav Brain Res 174:1-8.

Feltenstein MW, Henderson AR, See RE (2011) Enhancement of cueinduced reinstatement of cocaine-seeking in rats by yohimbine: sex differences and the role of the estrous cycle. Psychopharmacology 216: 53-62.

Feltenstein MW, Ghee SM, See RE (2012) Nicotine self-administration and reinstatement of nicotine-seeking in male and female rats. Drug Alcohol Depend 121:240-246.

Figlewicz DP, Sipols AJ (2010) Energy regulatory signals and food reward. Pharmacol Biochem Behav 97:15-24.

Figlewicz DP, MacDonald Naleid A, Sipols AJ (2007) Modulation of food reward by adiposity signals. Physiol Behav 91:473-478.

Fujihara H, Ueta Y, Suzuki H, Katoh A, Ohbuchi T, Otsubo H, Dayanithi G, Murphy D (2009) Robust up-regulation of nuclear red fluorescenttagged Fos marks neuronal activation in green fluorescent vasopressin 
neurons after osmotic stimulation in a double-transgenic rat. Endocrinology 150:5633-5638.

Geary N, Asarian L (1999) Cyclic estradiol treatment normalizes body weight and test meal size in ovariectomized rats. Physiol Behav 67:141-147.

Ghitza UE, Gray SM, Epstein DH, Rice KC, Shaham Y (2006) The anxiogenic drug yohimbine reinstates palatable food seeking in a rat relapse model: a role of $\operatorname{CRF}(1)$ receptors. Neuropsychopharmacology 31:2188-2196.

Ghitza UE, Nair SG, Golden SA, Gray SM, Uejima JL, Bossert JM, Shaham Y (2007) Peptide YY3-36 decreases reinstatement of high-fat food seeking during dieting in a rat relapse model. J Neurosci 27:11522-11532.

Goldman JM, Murr AS, Cooper RL (2007) The rodent estrous cycle: characterization of vaginal cytology and its utility in toxicological studies. Birth Defects Res B Dev Reprod Toxicol 80:84-97.

Grilo CM, Shiffman S, Wing RR (1989) Relapse crises and coping among dieters. J Consult Clin Psychol 57:488-495.

Herman CP, Polivy J (1975) Anxiety, restraint, and eating behavior. J Abnorm Psychol 84:66-72.

Huang YH, Schlüter OM, Dong Y (2011) Cocaine-induced homeostatic regulation and dysregulation of nucleus accumbens neurons. Behav Brain Res 216:9-18.

Ishikawa M, Mu P, Moyer JT, Wolf JA, Quock RM, Davies NM, Hu XT, Schlüter OM, Dong Y (2009) Homeostatic synapse-driven membrane plasticity in nucleus accumbens neurons. J Neurosci 29:5820-5831.

Johnson PM, Kenny PJ (2010) Addiction-like reward dysfunction and compulsive eating in obese rats: role for dopamine D2 receptors. Nat Neurosci 13:635-641.

Kalivas PW (2009) The glutamate homeostasis hypothesis of addiction. Nat Rev Neurosci 10:561-572.

Kenny PJ (2011) Common cellular and molecular mechanisms in obesity and drug addiction. Nat Rev Neurosci 12:638-651.

Koya E, Golden SA, Harvey BK, Guez-Barber DH, Berkow A, Simmons DE, Bossert JM, Nair SG, Uejima JL, Marin MT, Mitchell TB, Farquhar D, Ghosh SC, Mattson BJ, Hope BT (2009) Targeted disruption of cocaineactivated nucleus accumbens neurons prevents context-specific sensitization. Nat Neurosci 12:1069-1073.

Kramer FM, Jeffery RW, Forster JL, Snell MK (1989) Long-term follow-up of behavioral treatment for obesity: patterns of weight regain among men and women. Int J Obes 13:123-136.

Lynch WJ (2006) Sex differences in vulnerability to drug self-administration. Exp Clin Psychopharmacol 14:34-41.

Malinow R, Malenka RC (2002) AMPA receptor trafficking and synaptic plasticity. Annu Rev Neurosci 25:103-126.

Marinelli PW, Funk D, Juzytsch W, Harding S, Rice KC, Shaham Y, Le AD (2007) The CRF1 receptor antagonist antalarmin attenuates yohimbineinduced increases in operant alcohol self-administration and reinstatement of alcohol seeking in rats. Psychopharmacology (Berl) 195:345-355.

Mennerick S, Zorumski CF (1995) Paired-pulse modulation of fast excitatory synaptic currents in microcultures of rat hippocampal neurons. J Physiol 488:85-101.

Morgan JI, Curran T (1991) Stimulus-transcription coupling in the nervous system: involvement of the inducible proto-oncogenes fos and jun. Annu Rev Neurosci 14:421-451.

Nair SG, Golden SA, Shaham Y (2008) Differential effects of the hypocretin 1 receptor antagonist SB 334867 on high-fat food self-administration and reinstatement of food seeking in rats. Br J Pharmacol 154:406-416.

Nair SG, Adams-Deutsch T, Epstein DH, Shaham Y (2009a) The neuropharmacology of relapse to food seeking: methodology, main findings, and comparison with relapse to drug seeking. Prog Neurobiol 89:18-45.

Nair SG, Adams-Deutsch T, Pickens CL, Smith DG, Shaham Y (2009b) Effects of the MCH1 receptor antagonist SNAP 94847 on high-fat foodreinforced operant responding and reinstatement of food seeking in rats. Psychopharmacology 205:129-140.

Nair SG, Navarre BM, Cifani C, Pickens CL, Bossert JM, Shaham Y (2011) Role of dorsal medial prefrontal cortex dopamine D1-family receptors in relapse to high-fat food seeking induced by the anxiogenic drug yohimbine. Neuropsychopharmacology 36:497-510.

Nance DM (1983) The developmental and neural determinants of the ef- fects of estrogen on feeding behavior in the rat: a theoretical perspective. Neurosci Biobehav Rev 7:189-211.

Paxinos G, Watson C (2005) The rat brain in stereotaxic coordinates, Ed 5. Amsterdam: Elsevier Academic.

Peterson CB, Mitchell JE (1999) Psychosocial and pharmacological treatment of eating disorders: a review of research findings. J Clin Psychol 55:685-697.

Pickens CL, Cifani C, Navarre BM, Eichenbaum H, Theberge FR, Baumann MH, Calu DJ, Shaham Y (2012) Effect of fenfluramine on reinstatement of food seeking in female and male rats: implications for the predictive validity of the reinstatement model. Psychopharmacology 221:341-353.

Pillitteri JL, Shiffman S, Rohay JM, Harkins AM, Burton SL, Wadden TA (2008) Use of dietary supplements for weight loss in the United States: results of a national survey. Obesity (Silver Spring) 16:790-796.

Polivy J, Herman CP (1999) Distress and eating: why do dieters overeat? Int J Eat Disord 26:153-164.

Polivy J, Coleman J, Herman CP (2005) The effect of deprivation on food cravings and eating behavior in restrained and unrestrained eaters. Int $J$ Eat Disord 38:301-309.

Richards JK, Simms JA, Steensland P, Taha SA, Borgland SL, Bonci A, Bartlett SE (2008) Inhibition of orexin-1/hypocretin-1 receptors inhibits yohimbine-induced reinstatement of ethanol and sucrose seeking in Long-Evans rats. Psychopharmacology 199:109-117.

Selye H (1956) The stress of life. New York: McGraw-Hill.

Shaham Y, Shalev U, Lu L, De Wit H, Stewart J (2003) The reinstatement model of drug relapse: history, methodology and major findings. Psychopharmacology 168:3-20.

Shalev U, Marinelli M, Baumann MH, Piazza PV, Shaham Y (2003) The role of corticosterone in food deprivation-induced reinstatement of cocaine seeking in the rat. Psychopharmacology 168:170-176.

Shepard JD, Bossert JM, Liu SY, Shaham Y (2004) The anxiogenic drug yohimbine reinstates methamphetamine seeking in a rat model of drug relapse. Biol Psychiatry 55:1082-1089.

Stewart J, Woodside BC, Shaham Y (1996) Changes in ovarian hormones do not affect the initiation of intravenous self-administration of heroin in the female rat. Psychobiology 24:154-159.

Suemaru S, Dallman MF, Darlington DN, Cascio CS, Shinsako J (1989) Role of alpha-adrenergic mechanism in effects of morphine on the hypothalamopituitary-adrenocortical and cardiovascular systems in the rat. Neuroendocrinology 49:181-190.

Ungless MA, Whistler JL, Malenka RC, Bonci A (2001) Single cocaine exposure in vivo induces long-term potentiation in dopamine neurons. Nature 411:583-587.

Van den Oever MC, Goriounova NA, Li KW, Van der Schors RC, Binnekade R, Schoffelmeer AN, Mansvelder HD, Smit AB, Spijker S, De Vries TJ (2008) Prefrontal cortex AMPA receptor plasticity is crucial for cueinduced relapse to heroin-seeking. Nat Neurosci 11:1053-1058.

Van den Oever MC, Lubbers BR, Goriounova NA, Li KW, Van der Schors RC, Loos M, Riga D, Wiskerke J, Binnekade R, Stegeman M, Schoffelmeer AN, Mansvelder HD, Smit AB, De Vries TJ, Spijker S (2010a) Extracellular matrix plasticity and GABAergic inhibition of prefrontal cortex pyramidal cells facilitates relapse to heroin seeking. Neuropsychopharmacology 35:2120-2133.

Van den Oever MC, Spijker S, Smit AB, De Vries TJ (2010b) Prefrontal cortex plasticity mechanisms in drug seeking and relapse. Neurosci Biobehav Rev 35:276-284.

Wang Y, Zhang QJ, Liu J, Ali U, Gui ZH, Hui YP, Wang T, Chen L, Li Q (2010) Noradrenergic lesion of the locus ceruleus increases the firing activity of the medial prefrontal cortex pyramidal neurons and the role of alpha2-adrenoceptors in normal and medial forebrain bundle lesioned rats. Brain Res 1324:64-74.

Wolf ME, Ferrario CR (2010) AMPA receptor plasticity in the nucleus accumbens after repeated exposure to cocaine. Neurosci Biobehav Rev $35: 185-211$.

Wu LJ, Kim SS, Li X, Zhang F, Zhuo M (2009) Sexual attraction enhances glutamate transmission in mammalian anterior cingulate cortex. Mol Brain 2:9.

Yassin L, Benedetti BL, Jouhanneau JS, Wen JA, Poulet JF, Barth AL (2010) An embedded subnetwork of highly active neurons in the neocortex. Neuron 68:1043-1050. 